\title{
PENINGKATAN PRODUKTIVITAS KERJA \\ DENGAN MODEL KEPEMIMPINAN PROFETIK
}

\section{ENHANCING WORK PRODUCTIVITY WITH PROPHETIC LEADERSHIP MODEL}

\author{
Ahmad Yasser Mansyur \\ Fakultas Psikologi Universitas Negeri Makassar (UNM) Makassar \\ E-mail: ahmadyasser_mansyur@yahoo.com
}

\begin{abstract}
ABSTRAK
Discourse of leadership styles in this research is the concept of modern leadership that can be used for developing the theory of intrinsic leadership. This research is aimed to determine the influence of prophetic leadership style on the personal prophetic leadership and work productivity. Demographic aspects were also examined to look at the differences in variables. By using the experimental approach of this study include 31 employees BMT and Cooperative Sharia in Makassar. The results show GK-pro training can increase the value of personal prophetic leadership and employee productivity. Demographic aspects showed differences in the variables. This research produces one brand new concept intrinsic leadership based on sharia that is beneficial for the development of knowledge in Islamic Psychology discourse.
\end{abstract}

Key words: personal prophetic leadership, work productivity

\begin{abstract}
ABSTRAK
Wacana gaya kepemimpinan profetik dalam kajian ini merupakan konsep kepemimpinan mutakhir yang dapat menjadi bahan kajian penting untuk mengembangkan teori kepemimpinan bersifat intrinsik. Penelitian ini bertujuan menguji pengaruh model gaya kepemimpinan profetik (GK-pro) terhadap personal prophetic leadership dan produktivitas kerja. Aspek demografi turut diuji untuk mengetahui perbedaannya dalam variabel yang dikaji. Dengan menggunakan pendekatan eksperimen penelitian ini mengikutkan 31 karyawan BMT dan Koperasi Syariah di Makassar. Hasil kajian menunjukkan pelatihan GK-pro dapat meningkatkan nilai personal prophetic leadership dan produktivitas kerja karyawan. Variabel-variabel yang dikaji didapati mempunyai perbedaan dari aspek demografi. Selain itu, kajian ini menghasilkan satu konsep kepemimpinan intrinsik berasas syariah yang bermanfaat bagi pengembangan kajian Psikologi Islami.
\end{abstract}

Kata kunci: personal prophetic leadership, produktivitas kerja

Allah SWT banyak memberikan kisah dari beberapa generasi (organisasi) di bumi ini yang mengalami kehancuran dan organisasi yang dapat bertahan dalam perubahan lingkungannya. Hal ini dapat diketahui dari firman Allah SWT dalam alQur`an surat al-An`aam ayat 6 yang artinya: Apakah mereka tidak memperhatikan berapa banyak generasi yang telah Kami binasakan sebelum mereka, pada- hal (generasi itu) telah Kami teguhkan kedudukan mereka di muka bumi, yaitu keteguhan yang belum pernah Kami berikan kepadamu, dan Kami curahkan hujan yang lebat atas mereka dan Kami jadikan sungai-sungai mengalir di bawah mereka, kemudian Kami binasakan mereka karena dosa mereka sendiri, dan Kami ciptakan sesudah mereka generasi yang lain (QS. Al-An`aam: 6) 
Firman Allah SWT dalam surat alAn `am ayat 6 itu menjadi pelajaran agar manusia dapat kembali pada jalan kebenaran (sesuai hukum syariah) dan agar dapat menyesuaikan diri terhadap perubahan lingkungan yang terjadi. Nilai-nilai hukum syariah itu mengatur kehidupan ibadah dan hal-hal yang bersifat muamalah, seperti halal-haram, mengatur perilaku yang tidak boleh dilakukan, yaitu riba, judi, zhalim (aniaya), gharar (penipuan), barang haram, maksiat, dan risywah (suap) (Luwu, 2011).

Era modern pada masa kini ditandai dengan perubahan lingkungan yang cepat dan kemajuan teknologi informasi. Di Indonesia, terdapat fenomena organisasi yang bertahan dan dapat merespon secara baik terhadap perubahan lingkungan organisasi. Pada tahun 2007 banyak organisasi mengalami gulung tikar. Menurut Agustianto (2008), dampak dari krisis ekonomi itu sekitar 80 persen perusahaan, unit usaha dan bank konvensional mengalami negative spread sehingga berakibat pada proses likuidasi atau dimerger dengan bank lain. Seperti dibentuknya Bank Mandiri yang dulunya dari bank Exim, Bapindo, Bumi Daya dan Dagang Negara. Selanjutnya, masih menurut Agustianto, kondisi itu berbeda dengan perbankan yang dikelola secara syariah. Perbankan syariah tidak mengalami likuidasi.

Hingga kini lembaga-lembaga perbankan syariah ataupun lembaga keuangan nonbank di Indonesia menunjukkan perkembangan yang sangat pesat. Berkenaan dengan itu Haliding (2011) menyatakan pencapaian perbankan syariah terus mengalami peningkatan dalam jumlah bank. Dalam rentang lima tahun (20052010), pertumbuhan perbankan syariah mengalami lonjakan lebih dari dua kali lipat. Selain itu, menurut Luwu (2011), sampai tahun 2010 aset perbankan syariah mencapai 100 trilyun dengan 6 juta nasabah serta 20 ribu tenaga kerja. Kemudian pada tahun 2011 perkembangan perbankan syariah diperkirakan tumbuh sampai 50 persen sehingga perbankan syariah menjadi industri besar. Perkembangan lembaga ekonomi syariah (LES) tidak hanya di perkotaan saja, namun juga di daerah-daerah. Seperti yang dikabarkan Makassar Antara News bahwa Mamuju mengembangkan LES dan unit usaha koperasi sampai ke tingkat desa (Antara News, 2012).

Fenomena organisasi di atas telah membawa pemahaman bahwa organisasi yang dikelola secara syariah (berdasar hukum Islam) dapat terus berkembang di tengah dinamika perubahan iklim lingkungan organisasi. Sedangkan organisasi yang dikelola secara konvensional cenderung mengalami masalah dan lambat merespon serta beradaptasi terhadap perubahan lingkungan yang terjadi. Fakta itu sesuai dengan pernyataan Luwu (2011) bahwa pengalaman dari robohnya struktur pondasi ekonomi Indoensia di tahun 1997 menyadarkan bangsa Indonesia bahwa ekonomi kapitalis sangat rentan dengan masalah.

Terlepas dari manajemen organisasi dan sistem syariah, ada dua alasan dasar bertahannya organisasi yang dikelola secara syariah dalam perspektif psikologi kepemimpinan, yaitu efektivitas kepe- 
mimpinan intrinsik dan adanya keadaan intrinsik anggota organisasi.

Pertama, efektivitas kepemimpin-an intrinsik. Kepemimpinan yang efektif sangat diperlukan dalam kehidupan moderen dan arus global masa kini dan masa depan yang ditandai dengan kehidupan yang serba teknikal dan profesional. Dalam keadaan tersebut, Hasan (2005) memperkirakan banyak orang dan pemimpin yang mengabaikan dimensi moral dan agama dalam kehidupan individu mahupun sosialnya. Senada dengan itu, Morris (2003) menyarankan agar pemimpin masa depan memiliki kepribadian dan nilai yang diyakini secara pribadi (spiritual). Adanya tantangan masa depan mengharuskan para pemimpin untuk mampu mengidentifikasi, memperkuat dan hidup sebagai model dari nilai-nilai inti (rule models of key core value) dari spiritual dan agama. Menurut McFadden dan Kozberg (2008), nilai-nilai agama dan spiritual mempunyai pengaruh yang besar terhadap makna hidup anggota organisasi sehingga organisasi mengalami outcomes (hasil) yang tinggi. Nilai-nilai inti itu telah hadir dan menjadi budaya organisasi yang dibawa oleh para pemimpin, karyawan, dan sistem yang dibangun berasas syariah.

Kedua, adanya keadaan intrinsik anggota organisasi. Perubahan lingkungan organisasi juga menuntut adanya perubahan paradigma dari para pemimpin untuk membawa organisasinya yang efektif sehingga outcomes organisasi dapat diraih secara maksimal. Ada beberapa strategi yang digunakan untuk mencapai outcomes organisasi, salah satunya dengan meningkatkan makna hidup, komitmen dan produktivitas melalui program pemberdayaan anggota organisasi. Menurut Rokhman (2002), pemimpin mempunyai peran strategis dalam proses pemberdayaan (empowerment) anggota organisasi. Salah satu proses itu adalah pemimpin menciptakan keadaan saling percaya antara anggota organisasi, melibatkan anggota organisasi dalam proses mengambil keputusan dan pemberian tanggung jawab terhadap bawahan. Hal itu akan membentuk keadaan intrinsik berupa kebermaknaan hidup dan komitmen pada anggota organisasi sehingga mampu mencapai produktivitas yang optimal.

Permasalahannya sekarang adalah belum ada satu bentuk konsep (model) baku yang dipakai secara bersama mengenai gaya kepemimpinan bersifat intrinsik yang berbasis syariah (kepemimpinan intrinsik-plus syariah) yang menjadi dinamika penyebab bertahannya dan meningkatnya outcomes organisasi pada Lembaga Ekonomi Syariah (LES) khususnya pebankan syariah. Selama ini organisasi syariah atau LES dalam mengelola konsep kepemimpinan dalam meningkatkan outcomes bergerak secara parsial (tidak terorganisasi). Misalnya saja, perbankan syariah dan asuransi syariah lebih mapan konsep kepemimpinannya dan outcomes organisasinya lebih baik dibanding dengan LES yang kecil (berada di tengah-tengah masyarakat) seperti BPR Syariah, koperasi syariah, pegadaian syariah dan Baitul Maal Wattamwil (BMT). 
Usaha penelitian ini merupakan terobosan baru dalam dunia psikologi organisasi dan psikologi kepemimpinan Islam, serta memberi manfaat dalam pengembangan dan penerapan konsep ijtihad hukum Islam dalam LES di Indonesia. Hal ini didukung oleh Forum Riset IAEI (2011) yang menyatakan masih diperlukan sejumlah terobosan konseptual dalam memasuki dekade ketiga perbankan syariah nasional. Permasalahan tersebut merupakan motivasi bagi peneliti untuk berupaya menyatukan potensi LES dalam satu konsep model gaya kepemimpinan bersifat intrinsik sesuai nilai syariah (kultur organisasi) yang dimilikinya. Konsep gaya kepemimpinan yang peneliti tawarkan adalah gaya kepemimpinan profetik (kepemimpinan bersifat kenabian).

Gaya kepemimpinan ini bersifat intrinsik dan sesuai dengan nilai syariah yang ada dalam LES. Hal ini pula merupakan terobosan baru dalam dunia psikologi organisasi, psikologi kepemimpinan dan manajemen SDM, karena konsep itu belum banyak ditemukan dalam referensi dan belum menjadi model yang baku. Ada beberapa gaya kepemimpinan intrinsik yang sudah ada sebelumnya, seperti gaya kepemim-pinan transformasional (yang dibuat oleh Bass pada tahun 1979) dan gaya kepemimpinan spiritual (yang dipelopori oleh Fry tahun 2003). Namun kedua gaya kepemimpinan itu bersifat konvensional dan tidak sesuai dengan nilai-nilai (kultur) syariah yang berlaku dalam LES.

Berdasar fenomena dan rujukan hasil penelitan di atas, maka penelitian ini bermaksud menguji pengaruh pelatihan gaya kepemimpinan profetik terhadap produktivitas kerja. Fokus utama penelitian ini adalah pada gaya kepemimpinan profetik. Ini dimaksudkan agar menjadi wacana penting dalam pengembangan konsep gaya kepemimpinan bersifat intrinsik guna meningkatkan produktivitas kerja karyawan dan organisasi di tengah perubahan lingkungan global. Adapun hipotesis yang diajukan adalah pelatihan kepemimpinan profetik efektif dalam meningkatkan produktivitas kerja.

\section{METODE PENELITIAN}

\section{Subjek}

Penelitian ini menggunakan jenis penelitian eksperimen rancangan pre-test post-test group design dengan jumlah peserta sebanyak 31 orang karyawan dari BMT dan Koperasi Syariah se Makassar. Adapun demografi tersebut dapat dilihat dalam tabel 1 .

Tabel 1. Subjek penelitian dalam demografi $(N=31)$

\begin{tabular}{llcc}
\hline Demografi & Spesifikasi & Jumlah Subjek & Persen \\
\hline Jenis kelamin & Laki-laki & 19 & 59,4 \\
& Perempuan & 12 & 37,5 \\
Pernikahan & Menikah & 24 & 75,0 \\
& Tidak menikah & 7 & 21,9 \\
\hline
\end{tabular}


Metode Pengamblan Data

Pengambilan data dilakukan dengan menggunakan dua skala, yaitu skala produktivitas kerja dan skala kepemimpinan profetik. Dua skala tersebut telah memiliki reliabilitas yang memadai.

Tabel 2. Alat ukur dan reliabilitasnya

\begin{tabular}{llcc}
\hline \multicolumn{1}{c}{ Alat ukur } & \multicolumn{1}{c}{ Indikator } & Sumber & Reliabilitas \\
\hline Produktivitas kerja & $\begin{array}{c}\text { Efficiency in producing results, } \\
\text { benefits, or profits }\end{array}$ & Fry (2003) & .639 \\
Personal Prophetic & $\begin{array}{l}\text { 1. berorientasi ibadah } \\
\text { Leadership }\end{array}$ & Mansyur & .961 \\
& $\rightarrow$ SQ & $(2012)$ & \\
& 2. memiliki 4 sifat nabi (siddiq, \\
& fathonah, amanah dan tabligh) \\
& $\rightarrow$ IQ & \\
& 3. Humanis & \\
& $\rightarrow$ EQ & \\
\hline
\end{tabular}

\section{Intervensi}

Nama intervensi yang diberikan adalah pelatihan Gaya Kepemimpinan Profetik (GK-Pro). GK-Pro didasarkan pada konsep Mansyur (2009) tentang kepemimpinan profetik. Menurutnya, kepemimpinan profetik adalah nilai-nilai kepemimpinan yang bersumber dari Nabi Muhammad SAW dan AI-Qur`an untuk mengajak seseorang mencapai tujuan organisasi. Pada dasarnya pelatihan GKPro dimaksudkan untuk menghidupkan lima kriteria kepemimpinan profetik yang meliputi (1) berdasar iman, (2) berorientasi ibadah, (3) memiliki empat sifat nabi (siddiq, amanah, tabligh dan fathonah), (4) humanis, dan (5) memimpin dengan suara hati yang fitrah. Pelatihan diberikan dalam dua hari yang dilakukan dalam beberapa sesi pelatihan,

\section{Teknik Analisis Data}

Digunakan teknik analisis data uji beda (t-test) untuk menguji signifikansi perbedaan selisih skor rerata prates dan pascates skala untuk melihat efektivitas pelatihan.

\section{HASIL PENELITIAN}

Hasil uji beda (t-test) yang dilakukan dapat dilihat pada tabel 3 berikut ini: 
Tabel 3. Ringkasan hasil eksperimen GK-Pro

\begin{tabular}{lllccc}
\hline \multicolumn{1}{c}{ Variabel } & \multicolumn{1}{c}{ Jenis tes } & N & M & df & t \\
\hline Personal Prophetic & Prates & 31 & 43,4516 & 30 & $-1.263^{*}$ \\
Leadership & Pascates & 31 & 43,8387 & & \\
Produktivitas & Prates & 31 & 12,9355 & 30 & $-1.874^{*}$ \\
Kerja & Pascates & 31 & 13,4839 & & \\
$* \mathrm{p}<.05$ & & & & &
\end{tabular}

Dari tabel 3 didapatkan hasil, yaitu (1) rerata kepemimpinan profetik sebelum dan setelah tes adalah berbeda secara signifikan ( $\mathrm{t}(.30)=-1.263, \mathrm{p}<.05)$. Rerata kepemimpinan profetik setelah tes lebih tinggi (rerata $=43,8387$ ) dibanding rerata kepeimpinan profetik sebelum tes. (2) Rerata produktivitas kerja sebelum dan setelah tes adalah berbeda secara signifikan ( $\mathrm{t}(.30)=-1.874, \mathrm{p}<.05)$. Rerata produktivitas kerja setelah tes lebih tinggi (rerata $=43,8387$ ) dibanding rerata produktivitas kerja sebelum tes.

Dalam penelitian ini terdapat dua variabel, yaitu personal prophetic leadership dan produktivitas kerja. Kedua variabel itu juga dilihat perbedaannya berdasar jenis kelamin. Hasil analisis dapat dilihat pada tabel 3. Tabel 3 menunjukkan hasil analisis statistik uji t sebagai berikut: (1) Hasil menunjukkan rerata personal prophetic leadership (prates) di antara lakilaki dan perempuan adalah berbeda secara signifikan $(F(.29)=8,227, p<$ .05). Rerata personal prophetic leadership (prates) laki-laki (rerata $=43,9474$ ) lebih tinggi dibanding perempuan. (2) Hasil menunjukkan rerata personal prophetic leadership (pascates) laki-laki dan perempuan adalah tidak berbeda secara signifikan $(F(.29)=, 809, p>$.05). (3) Hasil menunjukkan rerata produktivitas kerja (prates) di antara laki-laki dan perempuan adalah berbeda secara signifikan $(F(.29)=9,425, p<.05)$. Rerata produktivitas kerja (prates) laki-laki (rerata $=13,1053$ ) lebih tinggi dibanding perempuan. (4) Hasil menunjukkan rerata produktivitas kerja (pascates) laki-laki dan perempuan adalah tidak berbeda secara signifikan $(F(.29)=1,043, p>.05)$.

Tabel 4. Personal prophetic leadership dan produktivitas kerja berdasar jenis kelamin

\begin{tabular}{llrllc}
\hline \multicolumn{1}{c}{ Variabel } & Jenis kelamin & N & M & Df & F \\
\hline Prophetic 1 & Laki-laki & 19 & 43,9474 & 29 & $8,227^{*}$ \\
& Perempuan & 12 & 42,6667 & & \\
Prophetic 2 & Laki-laki & 19 & 44,4211 & 29 &, 809 \\
& Perempuan & 12 & 42,9167 & & \\
Produktivitas 1 & Laki-laki & 19 & 13,1053 & 29 & $9,425^{*}$ \\
& Perempuan & 12 & 12,6667 & & \\
Produktivitas 2 & Laki-laki & 19 & 13,7895 & 29 & 1,043 \\
& Perempuan & 12 & 13,0000 & & \\
\hline
\end{tabular}

$* \overline{p<.05}$ 


\section{PEMBAHASAN}

Dengan hasil itu dapat dinyatakan bahwa pelatihan GK-pro dapat meningkatkan personal prophetic leadership dan produktivitas kerja karyawan. Seperti sebelumnya dinyatakan oleh McFadden dan Kozberg (2008) bahwa agama dan spiritual mempunyai pengaruh yang besar terhadap kinerja seseorang. Hal itu juga didukung oleh pendapat Feldman dan Snyder (2005) bahwa keimanan (keyakinan) seseorang akan membawa kepada kebermaknaan hidup secara intrinsik. Hasil penelitian menunjukkan model gaya kepemimpinan profetik (Gk-Pro) berpengaruh terhadap personal prophetic leadership dan produktivitas kerja.

Kajian ilmiah mengenai pengaruh kepemimpinan profetik terhadap produktivitas kerja belum banyak dilakukan. Hanya ada satu hasil penelitian yang berkaitan dengan produktivitas kerja, yaitu penelitian yang dilakukan oleh Dewi (2013) pada karyawan PLTU di Makassar. Hasil penelitian itu mendapatkan adanya pengaruh signifikan gaya kepemimpinan profetik terhadap produktivitas kerja karyawan. Kajian lainnya yang berhubungan dengan kepemimpinan profetik di antaranya oleh Mansyur (2013) yang menegaskan bahwa gaya kepemimpinan profetik mempunyai efek terhadap kesadaran otonomi dan motivasi internal karyawan melakukan aktivitasnya dalam organisasi. Selain itu penelitian yang dilakukan oleh Arifiyanto dan Budiharto (2008) menunjukkan kepemimpinan profetik (Nabi Muhammad SAW) berpengaruh dan mempunyai hubungan positif dengan kepuasan kerja karyawan dan guru yang bekerja di sekolah Islami Yogyakarta. Sedangkan Perbawa dan Sarasi (2014) menyatakan model kepemimpinan profetik dapat mengembangkan program Pembinaan Sumber Daya Manusia di lembaga Nurul Fikri Indonesia. Hasil tersebut merupakan fenomena menarik, di mana gaya kepemimpinan profetik merupakan gaya kepemimpinan intrinsik yang relatif baru dalam dunia kepemimpinan di era moderen ini

Ada kamungkinan efektifnya pelatihan gaya kepemimpinan profetik karena pelaksaanaan penelitian ditempatkan pada organisasi berdasar Islam dan subjek penelitiannya adalah muslim. Kemudian Mudjiono (2002) menyatakan adanya pengaruh nilai-nilai kepemimpinan nabi Muhammad SAW yang sangat besar bagi kehidupan organisasi. Menurut Mansyur (2009), kepemimpinan profetik adalah nilai-nilai kepemimpinan yang bersumber dari Nabi Muhammad SAW dan AlQur`an untuk mengajak seseorang mencapai tujuan organisasi. Kepemimpinan profetik mempunyai lima kriteria, yaitu (1) berdasar iman, (2) berorientasi ibadah, (3) memiliki empat sifat nabi (siddiq, amanah, tabligh dan fathonah), (4) humanis, dan (5) memimpin dengan suara hati yang fitrah.

Selain itu dalam Al-Qur`an memuat banyak konsep dasar kerja bagi seorang muslim yang senantiasa berorientasi ibadah yang mengandung makna komitmen intrinsik dan produktivitas kerja. Sebagaimana hal tersebut termak-tub dalam Al-Qur`an surat At-Taubah ayat 105 
sebagai berikut: Dan Katakanlah: "Bekerjalah kamu, maka Allah dan RasulNya serta orang-orang mukmin akan melihat pekerjaanmu itu, dan kamu akan dikembalikan kepada (Allah) Yang Mengetahui akan yang ghaib dan yang nyata, lalu diberitakan-Nya kepada kamu apa yang telah kamu kerjakan (QS AtTaubah ayat 105).

Perlu dibahas perbedaan konsep gaya kepemimpinan intrinsik. Konsep kepemimpinan spiritual dengan kepemimpinan profetik dibangun dari dasar spiritual. Namun keduanya memiliki perbedaan dasar mengenai sumber spiri-tual itu. Konsep kepemimpinan spiritual dikembangkan oleh Fry sejak tahun 2003 tidak terkait dengan masalah ketuhanan dan tidak menyinggung sisi keruhanian manusia, melainkan mengarahkan spiritupal pada masalah makna hidup, nilainilai dan keutuhan diri di tempat kerja. Kepemimpinan spiritual bersumber dari nilai-nilai kemanusian yang bersifat duniawi dan berjalan secara alamiah. Misalnya, seseorang dapat menemukan makna spiritual itu dari bekerja. Sedangkan kepemimpinan profetik bersumber dari sisi keruhanian manusia yang diperoleh dari pendekatan diri pada Allah SWT dan didapatkan dari mencontoh nilai keteladanan nabi Muhammad SAW. Gaya kepemimpinan transformasional juga bersifat intrinsik, namun tidak mempunyai warna spiritual. Gaya kepemimpinan ini banyak diterapkan dalam organisasi moderen di masa ini.

Gaya kepemimpinan profetik tidak lepas dari nilai kepemimpinan yang ada pada Muhammad SAW. Istilah profetik berasal dari kata prophet yang berarti nabi atau rasul (Echols \& Shadily 1996). Profetik sendiri berarti bersifat kenabian. Jadi, kepemimpinan profetik adalah kepemimpinan bersifat kenabian. Penelitian mengkhususkan konsep profetik pada kepemimpinan Muhammad SAW (sebagaimana termaktub dalam al-Qur`an surah al-Maidah ayat 55). "Sesungguhnya wali (pemimpin) kamu hanyalah Allah, Rasul-Nya, dan orang-orang yang beriman, yang mendirikan sholat dan menunaikan zakat, seraya mereka tunduk (kepada Allah)" (QS. Al Maidah: 55)

Antonio (2007), dalam buku yang berjudul "Muhammad The Super Leader Super Manager", mencoba melihat Rasulullah SAW dengan kaca mata baru yang lebih luas yaitu bukan saja mengakui Rasulullah SAW sebagai nabi dan rasul tetapi juga menempatkannya sebagai pemilik traits of leadership dan models of management. Traits of Leadership Rasulullah SAW itu terdiri atas delapan bidang utama, yaitu Self development atau personal leadership, bisnis dan ekonomi, kepemimpinan keluarga, dakwah, sosial dan politik, pendidikan, sistem hukum, dan strategi militer. Oleh itu, figur Muhammad SAW menjadi pusat model kepemimpinan agama dan duniawi yang senantiasa relevan sepanjang zaman. Nabi Muhammad SAW sebagai AlQur`an yang hidup (the living Qur'an) yang hingga kini umat manusia dapat mengikuti karakternya.

Menurut Mansyur (2009), perbedaan di antara tiga gaya kepemimpinan intrinsik itu terletak pada aspek konvensional dan syariah (perbedaan gaya 
kepemimpinan intrinsik itu dapat dijelaskan dalam gambar 4. Gaya kepemimpinan spiritual dan gaya kepemimpinan transformasional bersifat konvensional. Sementara itu gaya kepemimpinan profetik bersifat syariah.

Dapat dikatakan, gaya kepemimpinan profetik merupakan gaya kepemimpinan bersifat intrinsik plus syariah (Pro+). Kepemimpinan profetik bersifat intrinsik plus syariah merupakan integrasi antara motivasi intrinsik individu dengan motivasi ilahiyah, di mana keduanya berdimensi dunia (hasanah - happines) dan akhirat (salamah - salvation), sehingga hal itu memunculkan aktivitas kehidupan individu, kelompok dan organisasi secara intrinsik. Oleh itu, wacana gaya kepemimpinan profetik dalam kajian ini merupakan konsep kepemimpinan mutakhir yang dapat menjadi bahan kajian penting untuk mengembangkan teori kepemimpinan bersifat intrinsik guna meningkatkan outcomes (hasil) organisasi di tengah perubahan lingkungan global. Gaya kepemimpinan intrinsik inilah yang sangat diperlukan organisasi dalam menata kehidupannya menghadapi perubahan lingkungan organisasi di era moderen.

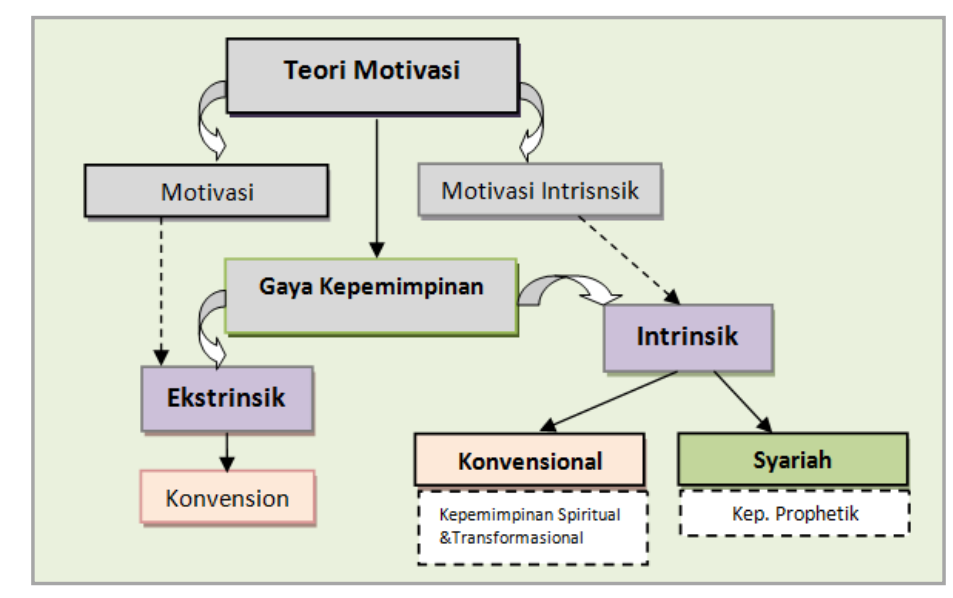

Gambar 4. Perbedaan gaya kepemimpinan intrinsik (Mansyur, 2009)

Berdasar telaah dari berbagai literatur penelitian tentang aspek demografi menunjukkan hasil yang berbedabeda antara satu dengan lainnya. Dewi (2006) menyatakan karakteristik biografikal pekerja seperti usia, jenis kelamin, status perkawinan, pendidikan, jumlah anggota keluarga dan masa kerja mempunyai pengaruh terhadap hasil organisasi. Lain halnya dengan hasil kajian Priambodo dkk (2007) yang menyatakan tidak terdapat perbedaan makna hidup berdasar jenis kelamin dan tingkat pendidikan. Begitu pula Prabowo dan Prawitasari (2007) melalui hasil penelitiannya menyatakan faktor karakteristik individu seperti usia, jenis kelamin, status perkawinan dan masa kerja tidak mem- 
pengaruhi kegiatannya dalam pekerjaan. Penulis menilai terjadinya perbedaan dan inkonsistensi tersebut disebabkan adanya faktor individu dan faktor lingkungan organisasi. Hal ini selaras dengan alQur`an surat al-Israa' ayat 84 dan alLail ayat 4. Katakanlah: 'Tiap-tiap orang berbuat menurut keadaannya (tabiat dan pengaruh Ingkungannya) masingmasing.' Maka Tuhanmu lebih mengetahui siapa yang lebih benar jalannya (QS. al-Israa : 84). Juga dapat ditemukan pada ayat berikut ini. Sesungguhnya (hasil) usaha kamu memang berbedabeda (QS. al-Lail: 4).

Ayat tersebut bermakna bahwa setiap individu mempunyai kemampuan dasar yang unik dan berbeda dengan individu lainnya. Perbedaan itu meliputi aspek biologis, psikologis, sosial dan spiritual. Aspek inilah yang membuat setiap individu berbeda dengan orang lain, termasuk kegiatannya dalam organisasi.

\section{SIMPULAN DAN SARAN}

\section{Simpulan}

Isu utama dalam penelitian ini adalah adanya organisasi bisnis dan sosial berdasar syariah (Islam) di Indonesia yang dapat bertahan di tengah perubahan lingkungan organisasi. Hal itu berhubungan dengan konsep gaya kepemimpinan intrinsik, khususnya gaya kepemimpinan profetik yang dapat mempengaruhi produktivitas kerja sehingga organisasi dapat beradaptasi dan bertahan dalam perubahan lingkungan di masa global ini.

\section{Saran}

Berikut dinyatakan rumusan penelitian dan manfaat yang didapati, serta saran untuk penelitian selanjutnya: Pertama: Dari hasil penelitian didapati bahwa pelatihan GK-pro dapat meningkatkan personal prophetic leadership dan produktivitas kerja karyawan. Hasil penelitian ini memberikan sumbangan pada perluasan wawasan dan konsep psikologi kepemimpinan khususya gaya kepemimpinan bersifat intrinsik. Selain itu, penelitian ini juga memperluas wawasan Psikologi Islami mengenai konsep kepemimpinan profetik yang dapat mendukung semangat Indigenous Psychology. Wacana gaya kepemimpinan profetik dalam kajian ini merupakan konsep kepemimpinan mutakhir yang dapat menjadi bahan kajian penting untuk mengembangkan teori kepemimpinan bersifat intrinsik guna meningkatkan outcomes (hasil) organisasi di tengah perubahan lingkungan global.

Kedua: Pada aspek demografi, didapatkan personal prophetic leadership (prates) laki-laki (rerata $=43,9474$ ) lebih tinggi dibanding perempuan. Kemudian, produktivitas kerja (prates) laki-laki (rerata $=13,1053$ ) lebih tinggi dibanding perempuan. Kajian ini menemukan jawapan dari adanya inkonsistensi pada hasil kajian literatur yang ada, karena setiap orang menghasilkan perilaku yang berbeda. Faktor inilah yang membuat hasil kajian tentang demografi tidak konsisten. Al-Qur`anul Karim membahasakan itu dengan konsep "fitrah" , sebagaimana terdapat dalam surah al-Israa 'ayat 84 yang maksudnya: "tiap-tiap orang berbuat menurut keadaannya masing-masing". 
Ketiga: Penelitian ini perlu dikembangkan pada wilayah organisasi lebih luas, dengan melibatkan organisasi konvensional dan responden dari latarbelakang agama yang berbeda.

Tulisan ini diakhiri dengan Firman Allah SWT dalam AI-Qur`an surah AlFurqaan ayat 53 yang menggambarkan perbedaan gaya kepemimpinan profetik dengan gaya kepemimpinan lainnya. "Dan Dialah yang membiarkan dua laut yang mengalir (berdampingan); yang ini tawar lagi segar dan yang lain asin lagi pahit; dan Dia jadikan antara keduanya dinding dan batas yang menghalangi" (QS. Al-Furqaan: 53).

Shodaqallaahu al-a 'adziim. Walahu a`lam.

\section{DAFTAR PUSTAKA}

Agustianto. (2008) Paradigma baru manajemen sumber daya manusia. Yogyakarta: Amara Books.

Antonio, M.S. (2007). Muhammad SAW: The super leader super manager. Jakarta: ProLM Centre.

Arifiyanto, D. \& Budiharto, S. (2008). Hubungan antara Kepemimpinan Profetik dengan Kepuasan Kerja. Naskah Publikasi Skripsi. Yogyakarta: Program Studi Psikologi Fakultas Psikologi dan Ilmu Sosial Budaya Universitas Islam Indonesia.

Bass, B. M. (1998). Transformational leadership: industrial, military, and educational impact. Mahwah, NJ: Erlbaum.
Bastaman, H. D. (1996). Meraih hidup bermakna: kisah pribadi dengan pengalaman tragis. Jakarta: Penerbit Paramadina.

Dewi, A. S. K. (2006). Analisis beberapa faktor yang mempengaruhi partisipasi karyawan (suatu kajian teori). Buletin Studi Ekonomi, 1 (1), 10-18.

Dewi. (2013). Pengaruh gaya kepemimpinan profetik dan transformasional terhadap produktivitas kerja: kajian pada karyawan PLTU Makassar. Skripsi (tidak diterbitkan). Makasssar: Fakultas Psikologi UNM.

Echols, J.M. \& Shadily, H. (1996). Kamus Inggris-Indonesia. Jakarta: Gramedia Pustaka Utama.

Feldman, D. B. \& Snyder, C. R. (2005). Hope and the meaningful life: theoretical and empirical associations between goal-directed thinking and life meaning. Journal of Social and Clinical Psychology, 24 (3), 401-421.

Fry, L. W. (2003). Toward a theory of spiritual leadership. The Leadership Quarterly, 14, 693-727.

Haliding, S. (2011). Arah dan Proyeksi Ekonomi Islam. Harian Fajar. 21 Januari 2011.

Hasan, M.T. (2005). Prospek Islam dalam menghadapi tantangan zaman. Jakarta: Lontabora Press Jakarta. 
Luwu, W.T. (2011). 12 Februari 2012. Ratulangi Pusat Bisnis Syariah Makassar, ekonomi.kompassiana.com,

Makassar.antaranews.com. 2012. 24 April 2012. Mamuju Kembangkan Lembaga Ekonomi Syariah ke Desa.

Mansyur, A.Y. (2009). Membangun konsep kepemimpinan profetik (prophetic leadership): alternatif solusi ke atas permasalahan kepemimpinan bangsa. Proseding Scientific Conference IV PPI UKM Facing the Future with Science.

Mansyur, A. Y. (2013). Psikologi Kepemimpinan: Pendekatan Intrinsik. Jakarta: Dapur Buku.

McFadden, S. \& Kozberg, R. C. (2008). Religious and spiritual supports for late-life meaning. Generations, 32 (2), 6-11.

Moejiono, I. (2002). Kepemimpinan and keorganisasian. Yogyakarta: UII Press.

Morris, T. (2003). Sang CEO itu bernama Aristoteles; Sukses berbisnis dengan kearifan filosofis. Bandung: Mizan.

Perbawa, A. \& Sarasi, V. (2014). The effectiveness of human resources development based on prophetic leadership model in PPSDMS Nurulfikri Bandung, Indonesia.

Prabowo, R. \& Prawitasari, J.E. (2007). Kinerja pegawai kantor Dinas Kesehatan Kota Tanjungbalai
Propinsi Sumatera Utara ditinjau dari faktor karakteristik individu dan lingkungan kerja. Working Paper Series No. 15, First Draft.

Rokhman, W. (2002). Upaya mencapai kesuksesan organisasi dalam menghadapi persaingan global. Dalam paradigma baru manajemen sumber daya manusia. Yogyakarta: Amara Books.

Ross, J. A. \& Gray, P. (2006). Transformasional leadership and teacher commitment to organizational values: the mediating effects of collective teacher efficacy. School Effectiveness and School Improvement, 17 (2), 179 - 199.

Salusu, J. (2000). Pengambilan keputusan stratejik untuk organisasi publik dan organisasi nonprofit. Gramedia Jakarta.

Singarimbun, M. (1987). Metode penelitian survey. Jakarta: LP3ES.

Tim Penerjemah. (2009). Al-Qur'an dan terjemahannya. PT. Sygma Examedia Arkanleema: Jakarta.

Walumbwa, F. O., Wang, P., Lawler, J. J., \& Shi, K. (2004). The role of collective efficacy in the relations between transformational leadership and work outcomes. Journal of Occupational and Organi-zational Psychology, 77, 515-530. 